\title{
Preparation and Some Properties of Nylon-4,2
}

\author{
R. J. GAYMANS, V. S. VENKATRAMAN, ${ }^{*}$ and J. SCHUIJER, Twente \\ University of Technology, Polymer Laboratories, P.O. Box 217, 7500 AE \\ Enschede, The Netherlands
}

\begin{abstract}
Synopsis
An attempt was made to produce a new short-chain alphatic polyamide nylon-4,2. This polyoxamide can be prepared by polycondensation of tetramethylene diamine and diethyl oxalate. A high molecular weight polymer ( $\eta_{\mathrm{inh}}=1.9$ from $0.5 \%$ solutions in $96 \%$ sulphuric acid) has been obtained by employing a two-step polycondensation method; the precondensation was carried out in solution at low temperatures $\left(20-140^{\circ} \mathrm{C}\right)$ and the postcondensation in the solid state at high temperatures $\left(250-300^{\circ} \mathrm{C}\right)$. The effect of solvent composition and reaction temperature on the prepolymerization and the effect of reaction time and temperature on the postcondensation were studied. We also investigated the influence of moisture during washing, storing, and the solid-state reaction on the polymerizability by the postcondensation. Nylon- 4,2 is soluble only in highly polar solvents such as trifluoroacetic acid (TFA), dichloroacetic acid, and $96 \%$ sulphuric acid. Films were cast from TFA. With these films we studied the IR spectrum, WAXS pattern, water absorption, and melting behavior. Nylon- 4,2 was found to melt at $388-392^{\circ} \mathrm{C}$, has a crystallinity of $70 \%$, and a low water absorption $(3.1 \%$ at $50 \% \mathrm{RH})$. The glass transition temperature of the dry sample was found to be at $\sim 120^{\circ} \mathrm{C}$ and for the wet sample at $-15^{\circ} \mathrm{C}$.
\end{abstract}

\section{INTRODUCTION}

Polyamides with a high amide content have been of interest for apparel fiber applications because of their possible similarity to wool and silk. We studied the little-known nylon-4,2, a polyamide which can be prepared from tetramethylene diamine (TMDA) and oxalic acid ester.<smiles>CC1CCCCCNC(=O)C(=O)NCCCCC1C</smiles>

Nylon-4,2 has the same amide content as nylon-3 and silk and it has special structural features. It is an even-even polyamide, where the dipole moments of the amide groups have alternating directions, which enhances the chain interaction, ${ }^{1}$ and it possesses oxamide groups, which according to Morgan and Pletcher ${ }^{2}$ have a trans structure. This means that in both crystalline and amorphous phase each oxamide group is coupled to just two other oxamide groups which implies a closer chain packing. Due to these special structural features we expect nylon-4,2 to have a well-packed crystalline phase, a high crystallinity, and possibly a better than average packed amorphous phase and consequently good fiber properties like high modulus, high glass transition temperature, and a low boiling water shrinkage.

* Present address: Shri Dinesh Mills Ltd., Padra Rd., P.O. Box 65, Vadodara, 390005, India.

Journal. of Polymer Science: Polymer Chemistry Edition, Vol. 22, 1373-1382 (1984) 
Polyoxamides have been studied for many years. ${ }^{2-12}$ The synthesis from oxalic acid is not a favorable route as the oxalic acid decomposes at high reaction temperatures. ${ }^{13}$ High molecular weight polyoxamides can be prepared from oxaloyl dichloride, ${ }^{3,4}$ from ring-opening polymerization of cyclic oxamides, ${ }^{5}$ or from a diester of oxalic acid. ${ }^{6-10}$ The syntheses from the diester have been carried out in two steps. The first step is a low-temperature reaction in solution with a low molecular weight prepolymer precipitating out. This is followed by a second step, the postcondensation, at higher temperatures $\left(250-300^{\circ} \mathrm{C}\right)$ to a high molecular weight polymer.

Depending on the temperature of melting the reaction in this second step is in the melt or in the solid state. With these syntheses catalysts sometimes employed. ${ }^{11,12}$ The polyoxamides $(-6,2,-8,2,-10,2 \text {, and }-12,2)^{7-10}$ are polyamides with high crystallinity and excellent fiber properties and are highly solvent resistant.

The aims of our study are to see whether nylon- 4,2 can be synthesized in a high molecular weight and to study some of its properties.

\section{EXPERIMENTAL}

\section{Materials}

The materials tetramethylenediamine (TDMA), diethyl oxalate (DEO), 1,2,4-trichlorobenzene (TCB), and 2-pyrrolidone were distilled prior to use. Dimethyl oxalate (DMO) was sublimed before use and phenol was used directly after freeing from moisture. Petroleum ether and diethyl ether, technical grade, were used as received.

\section{Polymerization}

The polycondensation reaction of TMDA with DEO was conducted in two steps. The prepolymers were prepared in presence of a solvent and the polymers were obtained by solid-state polymerization (SSP) of these prepolymers.

\section{Prepolymerization}

To a dry nitrogen flushed 1-L flang flask, fitted with a mechanical stirrer, a nitrogen inlet, and a distilling head, $250 \mathrm{~g}$ phenol and $250 \mathrm{~g}$ TCB were added. To this solvent mixture, which had been warmed up to $65^{\circ} \mathrm{C}, 22.44 \mathrm{~g}(0.255 \mathrm{~mol})$ TMDA and $36.5 \mathrm{~g}(0.250 \mathrm{~mol}) \mathrm{DEO}$ were added. The solution was warmed up to $140^{\circ} \mathrm{C}$ in $30 \mathrm{~min}$ and maintained at this temperature for $2 \mathrm{~h}$. During the polymerization ethyl alcohol was liberated and the initial homogeneous solution gradually turned cloudy and viscous. After $2 \mathrm{~h}$ the reaction mixture was cooled to about $80^{\circ} \mathrm{C}$ and poured into $2 \mathrm{~L}$ of petroleum ether. The precipitated polymer was washed twice with diethyl ether and dried in a vacuum oven.

\section{Postcondensation}

Small samples were postcondensed in the solid state in a fluidized bed reactor ${ }^{14}$ in a stream by dry nitrogen (e.g., for $4 \mathrm{~h}$ at $270^{\circ} \mathrm{C}$ ). The solid-state polymer- 
izations of larger batches were conducted in a tumble reactor, with nitrogen streaming over the reaction powder.

\section{Characterization}

Inherent viscosities $\left(\eta_{\text {inh }}\right)$ were determined from $0.5 \%$ solutions in $96 \%$ sulphuric acid at $25^{\circ} \mathrm{C}$. Films were cast from trifluoroacetic acid solutions. The infrared spectra were obtained from films. The melting behavior was studied with a du Pont 990 Thermal Analyzer DSC unit at a heating rate of $10^{\circ} \mathrm{C} / \mathrm{min}$. The peak temperatures were taken as the melting points. For wide-angle X-ray analysis (WAXS) a Kiessig pinhole vacuum camera was used.

\section{RESULTS AND DISCUSSION}

Since it is known that the monomers TMDA and DEO are quite unstable at high temperatures, mild polymerization conditions are preferred. In accordance with the methods used for other polyoxamides ${ }^{7,10}$ a precondensation in solution at low temperatures $\left(20-140^{\circ} \mathrm{C}\right)$ and a postcondensation in the solid state at $250-300^{\circ} \mathrm{C}$ were chosen.

\section{Solution Prepolymerization}

We studied the effect of the type of diester, the solvent, and the reaction temperature on the inherent viscosity of the polymer.

\section{Type of Ester}

The solution polymerization in TCB was conducted with two types of oxalic esters: dimethyl oxalate (DMO) and diethyl oxalate (DEO). In both cases a suspension was readily formed and after $2 \mathrm{~h}$ at $100^{\circ} \mathrm{C}$ the reaction was stopped. The precipitated polymers were analysed and the polymer from DMO had an $\eta_{\text {inh }}$ of 0.128 and that from DEO of 0.132 . As DEO was cheaper and easier to handle it was chosen for further study.

\section{Solvent and Temperature}

The solution polymerization was studied by carrying out the reaction in a number of solvents and at several temperatures. The results are presented in Table I.

If the reaction was carried out at $25^{\circ} \mathrm{C}$ in toluene precipitation started in 10 min and the powder was a low molecular weight polymer. The solubility of the prepolymer in toluene at $25^{\circ} \mathrm{C}$ was apparently very low. In an attempt to increase the solubility the reaction temperature was raised to $100^{\circ} \mathrm{C}$ but this made little difference to the viscosity $\eta_{\text {inh }}$ of the precipitated polymer. A good solvent for polyamidation of esters ${ }^{15}$ has been reported to be TCB, however, the use of this solvent gave little improvement. Pyrrolidone-2, which is a solvent sometimes used for the polyamidation reactions, did in our case keep the prepolymer in solution longer, but this had only a minor effect on the $\eta_{\text {inh }}$. A very strong solvent for polyamides is phenol and during a reaction in phenol the solution 
TABLE I

Effect of Prepolymerization Conditions on Inherent Viscosity

\begin{tabular}{lcclc}
\hline \multicolumn{1}{c}{ Solvent } & $\begin{array}{c}\text { Time } \\
(\mathbf{h})\end{array}$ & $\begin{array}{c}\text { Temperature } \\
\left({ }^{\circ} \mathrm{C}\right)\end{array}$ & \multicolumn{1}{c}{ Remarks } & $\eta_{\text {inh }}$ \\
\hline Toluene & 24 & 25 & Precipitate in 10 min & 0.119 \\
& 2 & 100 & Precipitate in 10 min & 0.126 \\
Pyrrolidone-2 & 2 & 100 & Precipitate in 30 min & 0.150 \\
TCB & 24 & 25 & Precipitate in 10 min & 0.128 \\
& 2 & 100 & Precipitate in 10 min & 0.132 \\
TBC/phenol 1:1 & 2 & 70 & Gel & 0.122 \\
& 2 & 130 & Gel & 0.146 \\
TBC/phenol 1:4 & 2 & 140 & Gel & 0.160 \\
Phenol & 2 & 140 & Solution & 0.140 \\
\end{tabular}

remained clear, but the $\eta_{\mathrm{inh}}$ of the prepolymer was found to be very low. Mixtures of TCB and phenol gave gelled reaction products and their viscosities were somewhat higher.

None of these solution polymerizations gave polymers of sufficiently high viscosities to be suitable for film making or fibre spinning, but these products can be used as starting material for further polymerizations. As the TCB-Phenol 1:1 solvent system gave the highest $\eta_{\text {inh }}$ this method was used for preparing samples to study the postcondensation in the solid state.

\section{Solid-State Postcondensation}

Nylon-4,2 is expected to have a high melt temperature $T_{m}>350^{\circ} \mathrm{C},{ }^{7}$ therefore the postcondensation cannot be carried out in the melt without strong degradation. In earlier studies on polyoxamides ${ }^{7,10}$ high molecular weight samples could be prepared with the postcondensation in the solid state.

In our case is in a fluidized the method of postcondensation bed reactor with nitrogen or steam as fluidizing gas. We studied the postcondensation at different temperatures for different times and looked at the effect of water.

\section{Reaction Temperature and Time}

The SSP in nitrogen for $4 \mathrm{~h}$ at the temperatures 270,283 , and $290^{\circ} \mathrm{C}$ (Table II) showed a steady increase in inherent viscosity with temperature. Increasing the reaction time (Table II) also increased the viscosity. Under these reaction

TABLE II

Influence of Reaction Temperature and Time by the Solid-State Postcondensations in Nitrogen

\begin{tabular}{cccl}
\hline Temperature & $\begin{array}{c}\text { Time } \\
(\mathrm{h})\end{array}$ & $\eta_{\text {inh }}$ & Appearance \\
\hline 270 & 4 & 1.93 & Yellow \\
283 & 4 & 2.08 & Light brown \\
290 & 2 & 2.26 & Light brown \\
290 & 4 & 2.40 & Light brown \\
290 & 16 & 2.70 & Light brown \\
\hline
\end{tabular}


TABLE III

Influence of Washing and Storing Conditions on the Viscosity after Postcondensation in the Solid State $\left(290^{\circ} \mathrm{C}, 4 \mathrm{~h}\right.$, Nitrogen)

\begin{tabular}{lc}
\hline & $\begin{array}{c}\eta_{\text {inh }} \\
\text { after SSP }\end{array}$ \\
\hline Prepolymer washed with ether and directly used & 2.3 \\
Prepolymer washed with water and directly used & 0.71 \\
Prepolymer washed with ether and stored for 6 months at $25^{\circ} \mathrm{C}, 50 \% \mathrm{RH}$ & 0.59 \\
\hline
\end{tabular}

conditions samples with a very high molecular weight can be synthesized. A high molecular weight is necessary for solution spinning. All the samples were found to be coloured, the polymer prepared at the lowest temperature somewhat less than the others.

\section{Water}

By conducting the polymerization on a larger scale, some batches could not be postcondensed to high molecular weights. One of the reasons for this might be the hydrolysis of the ester groups in the prepolymer. In order to study the susceptibility of the prepolymer ester endgroups to hydrolysis we varied the washing procedures, the effect of the storing conditions, and the presence of steam during SSP on the postcondensation of a prepolymer. We also studied the effect of steam on an already postcondensed sample.

If a prepolymer is prepared in a TCB/phenol mixture the reaction mass is a solid gel. The prepolymer can be obtained by precipitating the gel with petroleum ether and washing twice with ether. It was found that the resulting polymer still contained some phenol. To get rid of this last phenol it had to be washed a few extra times and this could be done with either ether or water. The effect of this last washing step was studied and the results are given in Table III. As can be seen the ether-washed sample was excellent postcondensable while the water-washed sample did not postcondense well. This suggests hydrolysis of the ester end group in the prepolymer to the less reactive acid end group.

Normally the prepolymers were postcondensed soon after they were obtained. If, however, a prepolymer was stored for 6 months at atmospheric conditions $\left(20^{\circ} \mathrm{C}, 50 \% \mathrm{RH}\right)$ it did not postcondense well (Table III). Again ester hydrolysis might be the cause.

Sometimes the SSPs on nylons are carried out with steam instead of nitrogen in order to prevent the formation of ge ${ }^{16,17}$ and color. ${ }^{18}$ A SSP of our prepolymer

TABLE IV

Effect of Steam (1 Bar) by the SSP

\begin{tabular}{|c|c|c|c|c|c|c|}
\hline & $\begin{array}{c}\text { Gas } \\
\text { (1 bar) }\end{array}$ & $\begin{array}{l}\text { SSP reaction } \\
\text { conditions } \\
\text { Temp. } \\
\left({ }^{\circ} \mathrm{C}\right)\end{array}$ & $\begin{array}{l}\text { Time } \\
\text { (h) }\end{array}$ & $\begin{array}{c}\eta_{\text {inh }} \\
\text { (before } \\
\text { SSP) }\end{array}$ & $\begin{array}{c}\eta_{\text {inh }} \\
\text { (after } \\
\text { SSP) }\end{array}$ & Remarks \\
\hline Prepolymer & $\mathrm{N}_{2}$ & 290 & 4 & 0.163 & 2.3 & Light brown \\
\hline Prepolymer & $\mathrm{H}_{2} \mathrm{O}$ & 290 & 4 & 0.163 & 0.28 & White \\
\hline Polymer & $\mathrm{H}_{2} \mathrm{O}$ & 290 & 0.5 & 2.3 & 0.47 & - \\
\hline Polymer & $\mathrm{H}_{2} \mathrm{O}$ & 290 & 2 & 2.3 & 0.43 & - \\
\hline
\end{tabular}


TABLE V

Solubilities

\begin{tabular}{ll}
\hline Solvent used & Solubility \\
\hline Trifluoroacetic acid & Soluble \\
Dichloroacetic acid & Soluble \\
Sulphuric acid $96 \%$ & Soluble \\
Hot SbCl $_{3}$ & Soluble \\
Formic acid $90 \%$ & Insoluble \\
Hot, aqueous phenol & Insoluble \\
Dimethylacetamide & Insoluble \\
\hline
\end{tabular}

with steam as fludizing gas resulted in a colorless product but the molecular weight had not increased (Table IV).

If a high molecular weight sample was steam treated at $290^{\circ} \mathrm{C}$ in the reactor (Table IV) the viscosity decreased strongly.

To obtain a high molecular weight material water contact should be avoided during precipitation, washing, storing, and SSP of the prepolymer. At $290^{\circ} \mathrm{C}$ the polymer itself also seems to be easily hydrolyzed.

\section{STRUCTURES AND PROPERTIES}

\section{Solubility}

The solubility of a polymer with a well-packed crystalline phase tends to be low. The results of the solubility tests are given in Table V. At room temperature the polymer dissolved with relative ease in trifluoroacetic acid and dichloroacetic acid and slowly in concentrated sulphuric acid. At higher temperatures it dissolved in $\mathrm{SbCl}_{3}$ too. The polymer did not dissolve or even swell in formic acid and hot aqueous phenol. This is a notable feature as nylon-3 is said to dissolve readily in both formic acid and hot aqueous phenol. ${ }^{19}$ Nylon-4,2 is clearly very resistant to solvents. This also means that the analysis from solutions is difficult and that solution spinning is limited to only a very few solvent systems.

\section{Film Formation}

Films up to $0.5 \mathrm{~mm}$ thick were formed from $5 \%$ solutions of polymer in trifluoroacetic acid. The color of the film was light brown. Films could be formed from viscosities over 0.6 , but for films of good strength and flexibility a viscosity of at least 1.9 was needed.

\section{Infrared Analysis}

The infrared spectrum of a polymer film sample is identical with that reported in the literature (Fig. 1). ${ }^{20}$ The assignments of the respective bands are given in Table VI. The position of the $\mathrm{N}-\mathrm{H}$ stretching frequency at $3300 \mathrm{~cm}^{-1}$ is notable. This band position depends on the amide distances ${ }^{21}$ and as it has the same frequency as most other aliphatic polyamides the amide distance of $-4,2$ is not expected to differ from the other polyamides. 


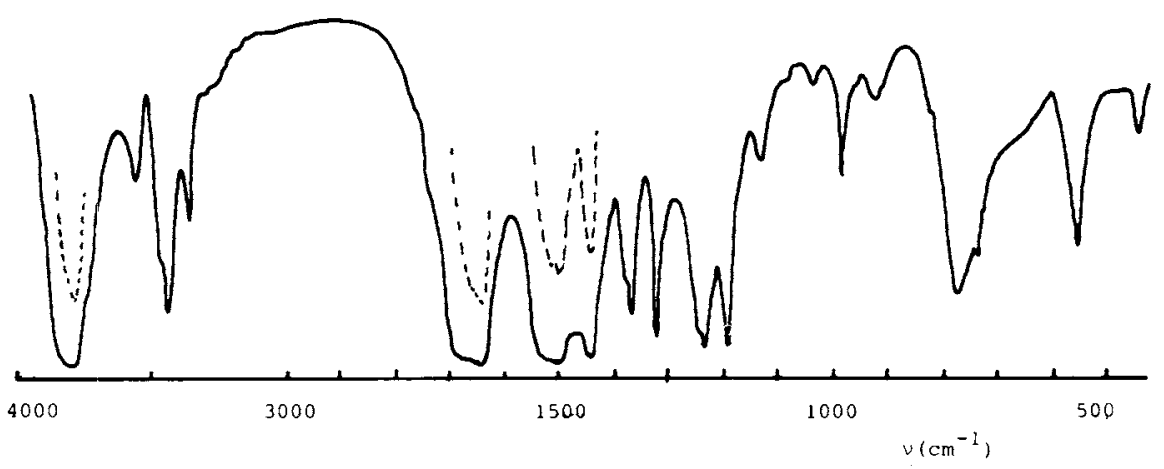

Fig. 1. Infrared spectrum of a solution cast film.

\section{X-Ray Analysis}

Nylon-4,2 is an even-even polyamide with an oxamide group. As the oxamide groups are trans according to Morgan and Pletcher ${ }^{2}$ a good chain interaction in both the amorphous and the crystalline phase and a high crystallinity are expected. For this study we used a solvent cast film, which was boiled up in water for $1 \mathrm{~h}$. The diffraction pattern showed several sharp bands and of these the interplanar spacings are given in Table VII as well as those of some other polyamides. The $d_{010}$ (the distance between the amide planes) of $-4,2$ is smaller than that of the other nylons.

The 4.26- $\AA$ spacing, which is a shoulder on the 4.60 - $\AA$ spacing, we have designated as the $d_{100}$ and the $460-\AA$ spacing as $d_{h k 2}$. The $d_{100}$ of $-4,2$ is smaller than that of the other nylons and this suggests that either the amide bond distance is smaller or that the angle between $d_{010}$ and $d_{100}$ is smaller. From the

TABLE VI

Infrared Data

\begin{tabular}{cll}
\hline $\begin{array}{c}\text { Bands at } \\
\text { wavenumbers } \\
\left(\mathrm{cm}^{-1}\right)\end{array}$ & $\begin{array}{c}\text { Intensity of } \\
\text { the band }\end{array}$ & \\
\hline 3300 & Very strong & $\mathrm{N}-\mathrm{H}$ band \\
3070 & Medium & $\mathrm{N}-\mathrm{H}$ band \\
2960 & Shoulder & $\mathrm{CH}_{2}$ band \\
2870 & Medium & $\mathrm{CH}_{2}$ band \\
1640 & Very strong & Amide I $(\mathrm{C}=\mathrm{O})$ band \\
1500 & Very strong & Amide II $(\mathrm{C}-\mathrm{H} ; \mathrm{N}-\mathrm{H})$ band \\
1460 & Strong & Unidentifiable; unique to polyoxamides \\
1370 & Strong & \\
1330 & Strong & Complex vibration of the amide group and $-\mathrm{CH}_{2}$ chain \\
1240 & Strong \\
1190 & Strong & Amide IV band \\
990 & Medium & Amide V band \\
780 & Shoulder & Amide VI band \\
560 & Medium & Amide VII band \\
450 & Medium &
\end{tabular}


TABLE VII

Wide-Angle X-Ray Data of Nylon-4,2 and Other Nylons

\begin{tabular}{cccccccc}
\hline & -4.2 & -4.6 & -6.6 & -6.2 & -8.2 & -10.2 & -3 \\
& & $(22)$ & $(23)$ & $(10)$ & $(10)$ & $(10)$ & $(23)$ \\
\hline$d_{010}$ & 3.56 & 3.74 & 3.73 & 3.75 & 3.79 & 3.81 & 3.78 \\
$d_{100}$ & 4.26 & 4.30 & 4.34 & 4.48 & 4.44 & 4.62 & 4.36 \\
\hline
\end{tabular}

TABLE VIII

Water Absorption

\begin{tabular}{lcc}
\hline & \multicolumn{2}{c}{ Humidities } \\
\cline { 2 - 3 } & $50 \% \mathrm{RH}$ & $100 \% \mathrm{RH}$ \\
\hline Cast film & 3.1 & 14.1 \\
Cast film heat pressed $\left(10 \mathrm{~min}, 240^{\circ} \mathrm{C}\right)$ & 2.8 & 9.3 \\
\hline
\end{tabular}

TABLE IX

Melting Behavior

\begin{tabular}{lccccc}
\hline & \multicolumn{2}{c}{ Melting temperature $\left({ }^{\circ} \mathrm{C}\right)$} & & \multicolumn{2}{c}{ Heats of fusion } \\
\cline { 2 - 3 } & Minor & Major & & $\Delta H_{\mathrm{f}}(\mathrm{J} / \mathrm{g})$ & $x_{\mathrm{c}}(\%)$ \\
\hline Prepolymer (powder) & 382 & 392 & 136 & 66 \\
Postpolymer (powder) & 380 & 391 & 148 & 72 \\
Postpolymer (film) & - & 388 & 154 & 75 \\
\hline
\end{tabular}

infrared analyses we expected the amide bond not to differ from the other nylons. From this it seems that the lower $d_{100}$ value must be due to a smaller angle between the $d_{010}$ and the $d_{100}$ planes. These results certainly indicate that $-4,2$ has a well-packed crystalline phase.

\section{Water Absorption}

The water absorption was measured on a solvent cast film. Care should be taken with the interpretation of these results as cast films can give much higher absorption values then melt pressed films. Therefore we studied the water absorption on both a cast film and a film which had an additional solid-state pressing $\left(10 \mathrm{~min}\right.$ at $\left.240^{\circ} \mathrm{C}\right)$. The results are given in Table VIII. Though the polymer is hydrophilic (due to its high amide content) relative low water absorption values were obtained. The heat pressed film has lower values than the other. This might indicate that a melt pressed film would have even lower values. These results compare well with the results on nylon- $3,{ }^{19}$ for which a water absorption of $7-9 \%$ at $65 \% \mathrm{RH}$ was reported.

\section{Melting Behavior}

The melting temperatures of polyamides depend on the amide content, the structural regularity, and the thermal history of the sample. With DSC the melting behavior was studied and the results are given in Table IX.

From the heats of fusion and an estimated value for a $100 \%$ crystalline sample of $(205 \mathrm{~J} / \mathrm{g})^{24}$ a rough idea of the crystallinity could be obtained. The melting 
temperature of the major endotherm for the prepolymer and polymer powder was $392^{\circ} \mathrm{C}$ and for the film $388^{\circ} \mathrm{C}$. These temperatures are high compared to the $340^{\circ} \mathrm{C}$ of nylon-3. ${ }^{19}$ The calculated crystallinities were all three in the order of $70 \%$ which is very high too. These high melting temperatures will make melt polymerization and melt processing impossible.

\section{Glass Transition}

As with other polyamides no glass transition was observed with DSC. One of the ways of obtaining a $T_{g}$ is by studying the damping behavior with temperature. For this we used a torsion pendulum apparatus which is not really suited for films. For a dried sample the $T_{g}$ was $120^{\circ} \mathrm{C}$, for a sample conditioned at $50 \% \mathrm{RH}$ the $T_{g}$ was $70^{\circ} \mathrm{C}$, and for a wet sample the $T_{g}$ was $-15^{\circ} \mathrm{C}$.

The dry glass transition is high for an aliphatic polyamide, but for some other short-chain polyamides very high glass transitions have also been reported, ${ }^{20,25}$ for example, for nylon- 3 a temperature of $180^{\circ} \mathrm{C}$. On wetting the $T_{g}$ drops enormously. But the sample conditioned at $50 \% \mathrm{RH}$ has a $T_{g}$ well above room temperature. For textile fibre applications this high $T_{g}$ at $50 \% \mathrm{RH}$ is desirable.

\section{CONCLUSIONS}

Nylon-4,2 can be synthesized to high molecular weights starting from oxalic esters by a two-step process, the polymerization in solution at low temperatures and the SSP at $250-300^{\circ} \mathrm{C}$.

Nylon-4,2 has a very good crystalline packing and its crystallinity is high.

Although the material has a hydrophilic structure the water absorption is low and so is the solubility in several typical nylon solvent systems. The high glass transition temperature even of conditioned samples (at $50 \% \mathrm{RH}$ ) combined with a high crystallinity suggests that $-4,2$ might have excellent fiber properties like high initial modulus, small drop of modulus on wetting, good recovery properties, and possibly a low boiling water shrinkage.

If nylon- 4,2 could be synthesized colourless and spun easily, it would be a potential interesting fiber material.

The authors wish to thank Professor A. Bantjes for his active interest.

\section{References}

1. J. P. Hummel and P. J. Flory, Macromolecules, 13, 479 (1980).

2. P. W. Morgan and T. C. Pletcher, J. Polym. Sci. Polym. Chem. Ed., 18, 643 (1980).

3. Y. Chatani, Y. Ueda, H. Tadokoro, W. Deits, and O. Vogl, Macromolecules, 11, 636 (1978).

4. L. B. Sokolov, Interfacial Synthesis, F. Millich and C. E. Carraher, Jr., Eds., Dekker, New York, 1977, Vol. 1, pp. 141-165.

5. O. Vogl and A: C. Knight, Macromolecules, 1, 315 (1968).

6. S. J. Allen and J. G. N. Drewitt, U. S. Patent 2,558,031 (June 26, 1951) to Celanese Corp. of America.

7. G. S. Stamatoff and N. K. J. Symons, U.S. Patent 3,247,168 (April 19, 1966) to du Pont Co.

8. W. R. Sorenson and T. W. Cambell, Preparative Methods of Polymer Chemistry, Interscience, New York, 1961, pp. 85-86.

9. A. N. Zav'yalov, T. A. Sorokina, and T. B. Shabanova, Polym. Sci. U.S.S.R. A, 12, 2370 $(1970)$. 
10. S. W. Shalaby, E. M. Pearce, R. J. Fredericks, and E. A. Turi, J. Polym. Sci. Polym. Phys. Ed., $11,1(1973)$.

11. S. D. Bruck, U.S. Patent 2,977,340 (March 28, 1961) to du Pont Co.

12. S. D. Bruck, I\&EC Product Research and Development, 2, 119 (1963).

13. E. H. Pryde and J. C. Cowan, Condensation Monomers; J. K. Stille and T. W. Cambell, Eds., High Polymers, Vol. 27, Wiley-Interscience, New York, 1972, pp. 14-22.

14. R. J. Gaymans, J. Amirtharaj, and H. Kamp, J. Appl. Polym. Sci., 27, 2513 (1982).

15. E. Djodeyre, F. Carriére, and H. Sekiguchi, Eur. Polym. J., 15, 69 (1979).

16. K. W. Ramsey and J. H. Dunnill, U.S. Patent 3,240,804 (Jan. 7, 1969) to Brit. Nylon Spinners Ltd.

17. P. Schlack, Chemiefasern, 1,64 (1965).

18. R. J. Gaymans and E. H. J. P. Bour, Eur. Patent 0,038,094 (March 25, 1981) to Stamicarbon B.V.

19. J. Masamoto, K. Sasaguri, C. O. K. Yamaguchi, and H. Kobayashi, J. Appl. Polym. Sci., 14, 667 (1970).

20. D. O. Hummel, Atlas der Kunststof-Analyse, Carl Hanser Verlag, Munich, 1978, p. 380.

21. K. Nakamoto, M. Margoshes, and R. E. Rundle, J. Am. Chem. Soc., 77, 6480 (1955).

22. R. J. Gaymans, T. E. C. van Utteren, J. W. A. van den Berg, and J. Schuijer, J. Polym. Sci. Polym. Chem. Ed., 15, 537 (1977).

23. J. Masamoto, K. Sasaguri, C. Ohizumi, and H. Kobayashi, J. Polym. Sci. Polym. Phys. Ed., $8,1703(1970)$.

24. D. W. van Krevelen, Properties of Polymers, Elsevier, Amsterdam, 1976, Chap. V.

25. E. Wölfe and B. Stoll, Colloid Polym. Sci., 258, 300 (1980).

Received August 1, 1983

Accepted November 7, 1983 